International Journal of Current Microbiology and Applied Sciences

ISSN: 2319-7706 Volume 10 Number 10 (2021)

Journal homepage: http://www.ijcmas.com

\title{
Prevalence of Intestinal Opportunistic Parasites Infections among HIV Positive Children in the University Hospital Center Yalgado Ouédroago of Ouagadougou, Burkina Faso
}

\author{
Traoré Roukiatou $^{1 *}$, Zongo Cheikna ${ }^{1}$, Zongo Oumarou ${ }^{1,4}$, Ouédraogo Ganamé Abasse ${ }^{1}$, \\ Zida Adama ${ }^{2}$, Yonaba Caroline ${ }^{3}$, Traoré Yves ${ }^{1}$ and Savadogo Aly ${ }^{1}$ \\ ${ }^{1}$ Laboratory of Applied Biochemistry and Immunology, University Joseph Ki-ZERBO, \\ Burkina Faso \\ ${ }^{2}$ Parasitology Department - Mycology of the Yalgado Ouédroago University Hospital Center, \\ Burkina Faso \\ ${ }^{3}$ General Pediatrics Department of the Yalgado Ouédroago University Hospital Center, \\ Burkina Faso. \\ ${ }^{4}$ Science and Technology Training and Research Unit (UFR / ST), University Thomas \\ SANKARA, Burkina Faso \\ *Corresponding author
}

Keywords

Intestinal parasite, HIV; Children, Prevalence, CHUYO, Burkina Faso

Article Info

Accepted: 18 September 2021 Available Online: 10 October 2021
In Sub-saharan Africa, gastrointestinal parasites infections are widespread, particularly among immune deficient individuals. Prevalence of these infections varies from locality to other due to many factors. The present cross-sectional study aimed to assess the prevalence of intestinal parasites among HIV-positive children in the paediatric clinic at the University Hospital Yalgado Ouedraogo of Ouagadougou. A cross-sectional study was conducted in the University hospital of Ouagadougou from July to November 2015. Ninety-three (93) freshly issued stool samples were collected in HIV-positive children less than 15 years old. Stool samples were analysed for the presence of various intestinal parasites using direct microscopy, formol-ether concentration method, modified Ziehl Neelsen stain and Weber trichrome stain. The study included 93 HIV positive children. The prevalence of intestinal parasitic infection was $24.73 \%$ (23/93). The most detected parasites were Entamoeba coli (52.17\% for total detected parasites), Trichomonas intestinalis (21.73\%), Giardia intestinalis (8.65\%), Entamoeba histolytica (4.34\%). Patients with multi-infection ( 2 or 3 parasites) have been detected. The participants, 97.5\% (89/93) were on cotrimoxazole prophylaxis and $81.76 \%$ (76/93) were on ARV therapy. Despite the medical care given to the HIV-infected children, the prevalence of opportunistic intestinal is high at the University hospital Yalgado Ouédraogo (CHU-YO) and deserves special attention. 


\section{Introduction}

Human immunodeficiency virus/acquired immunodeficiency syndrome (HIV/AIDS) remains a major public health in sub-Saharan Africa. In Burkina Faso, the number of people living with the HIV was estimated at 110000 with 18000 children of less than 15 years at the end of 2014 (ONUSIDA/BF, 2015). HIV infection leads to a decrease of CD4 lymphocytes level in the body and this immunodeficiency situation favour many opportunistic infections including intestinal parasites. Gastrointestinal problems resulting from opportunistic parasitic infections in HIV/AIDS infected subjects often present as diarrhoea and significant disease has been recorded in $50-96 \%$ of cases worldwide with $90 \%$ prevalence rate reported in Africa (Oguntibeju, 2006). The intestinal parasites are the main agents responsible for severe chronic diarrhoea for the people infected by the HIV (Akinboand, 2010). Theses parasites are responsible for considerable morbidity and mortality in HIV/AIDS patients (Farthing, 2006; Kipyegen et al., 2012). Children are particularly vulnerable. There is a need to know the type of parasites involved, their prevalence in HIV/AIDS patients and to control the factors which leads to their propagation. Many factors such as climate, high population density, poverty, very low hygienic conditions and health education are known to play important role in the transmission of intestinal parasites (Harhay et al., 2010; Sangaré et al., 2015). Thus, the prevalence of these infections varies from country to country, region to region, medical center to medical center.

In Burkina Faso, intestinal parasites are considered as a major public health problem (Karou et al., 2011; Fortunato et al., 2014).Some epidemiological studies estimated their global prevalence at $54.7 \%$ throughout the country (Cissé et al., 2011). Different prevalence has been observed between sahelian area (38.9\% in the Sahel) and humid area $(65.8 \%$ in the East).

In Ouagadougou, the capital city of Burkina Faso, prevalence of 60.82 and $52.47 \%$ have been previously reported at Hospital Saint Camille of Ouagadougou (HOSCO) (Karou et al., 2011; Ouermi et al., 2012). In BoboDioulasso, the second biggest city of the country, Sangaré et al., (2015) reported a prevalence of $65.3 \%$ at the University Hospital SouroSanou. All these studies have been conducted on concerned all patients (HIV+ patients, HIV- patients, children and adults).

There are a few data about the situation of the prevalence level of opportunistic intestinal parasites in the CHU-YO. The present study aimed to assess the prevalence of opportunistic intestinal parasites among a vulnerable group of patients: immunocompromised children with HIV/AIDS in CHU-YO in order to undertake corrective actions in management and the treatment.

\section{Materials and Methods}

\section{Study design and area}

The study was cross-sectional involving HIV positive children. This cross-sectional study was carried out in the University hospital of Ouagadougou (CHU-YO) from July to November 2015. The CHU-YO is not only the biggest hospital of Ouagadougou, but also the biggest hospital of Burkina Faso.

\section{Study population}

All consenting patients aged from 0 to 15 years, who have been confirmed HIV positive and were registered patients of general paediatrics hospital. The inclusion criteria 
were: children who were HIV-positive children from 0 to 15 years and who's verbal and written informed consent was sought from the parents/guardians. Data about the included children for this study was obtained using structured questionnaire. The clinical file of each child was consulted and the following information's were noted: age, sex, drug history, CD4 lymphocytes level, the immunodeficiency status, family and social history.

\section{Specimen collection and laboratory processing}

The stool samples were collected in sterile plastic containers and labelled in the service of general paediatrics. All of the collected stool samples were transported immediately to the Parasitology-Mycology Service for analysis. A direct wet mount of the stool sample was prepared and examined for the presence of motile intestinal parasites and trophozoites under a light microscope. Concentration of parasites was determined using formol-ether concentration techniques (Cheesbrough, 1999) to identify the eggs and cysts. The Modified Ziehl-Neelsen stain (Casemore, 1991) and the Weber trichrome stain (Weber et al., 1992) were used to identify Cryptosporidium sp., Microsporidium sp. and other intestinal protozoa.

\section{Ethical considerations}

Ethical approval was obtained. Participation in the study was voluntary and verbal or written informed consent was obtained from all the parents/guardians. The information obtained from the patients for the study was kept confidential.

\section{Statistical analysis}

The data obtained was analyzed with Epi Info version 7 using simple descriptive statistics.
Tests for significance for associations computed for categorical variables were based on the chi-square. p-values less than 0.05 $(\mathrm{p}<0.05)$ were regarded as statistically significant.

\section{Results and Discussion}

\section{Characteristics of study population}

The study included 93 HIV-positive children. Among these participants, $50(53.76 \%)$ were male and $43(46.24 \%)$ females, with a median age (range) of $9 \pm 3$ (5-10) years. Among the study participants, $76(81.72 \%)$ were on antiretroviral (ART); 89 (97.5\%) were on Cotrimoxazole (CTX) prophylaxis and $67.74 \%$ of children had no immunodeficiency. Clinical, therapeutic, biological and sociodemographic characteristics of the study participants are summarized in Table I.

\section{Prevalence of intestinal parasitic infestation in HIV-positive children}

Intestinal parasites have been detected in 23 children. That gives a prevalence rate of $24.7 \%(23 / 93)$ in the study population. In this study 4 parasites species were detected: Entamoeba histolytica, Giardia lamblia, Entamoeba coli and Trichomonas intestinalis. Entamoeba coli exhibited the highest prevalence $(12.9 \%)$, followed by $T$. intestinalis $(5.38 \%)$, G. intestinalis (2. 15\%), E. histolytica (1.07\%). Within the multiinfected samples, duel and tri-infections accounted for (2.15) and (1.07\%) (Table II).

The distribution of the parasitized children according to the age groups showed that the age group from 5 to 10 years was most affected with a frequency of $29.79 \%$. However, there was no significant difference in parasitic infections associated with the age groups (Table I). Seventy four percent $(74 \%)$ $(10 / 13)$ of the symptomatic patients had 
intestinal parasites. This association was statistically significant $(\mathrm{p}=0)$. The intestinal parasites were observed in different immunological stage with a frequency raised at the children who did not present immunizing deficit. No statistically significant correlations were observed between their immunological condition and parasitic infections ( $p>0.05)$. The association was not statistically significant between the CTX and ART use and parasitic infections. $G$. intestinalis and $T$. intestinalis were significantly associated with digestive disorders (Table III).

In this study, there was prevalence $(24.7 \%)$ of intestinal parasites in HIV children at CHUYO. The prevalence obtained in this study is higher than earlier findings in a similar study reported by Ouermi (2012) from Saint Camille Medical Center (18.8\%). It has been established those parasitological infections varies from region to other or from hospital to hospital due to many factors including environmental, social and economical factors such as poverty, malnutrition, personal and community hygiene, population density, unavailability of drinking water, poor sanitary facilities and hot and humid tropical climate (Singh et al., 2013; Sangaré et al., 2015; Amer et al., 2016; Jayalakshmi and Dharanidevi, 2016). The difference could also be due to coproparasitological techniques used. In the study, modified Ziehl-Neelsen increased the sensitivity.

The age group of 5 to 10 years was mostly affected with intestinal parasites, followed by the group of 1 to 5 years. This could be explained as the risk of acquiring an infection increases with age as a result of exposure from interaction or adventure, which is usually the rule with growing up. However, there was no significant difference in parasitic infections associated with the age groups. This observation is similar to the results obtained by Oyedeji et al., (2015) in Nigeria who showed that the overall prevalence of intestinal parasites in the group of 5 to 10 years was high.

The prevalence of parasitic infection was significantly higher in patients with digestive disorders than in patients without digestive disorders (73. $92 \%$ vs16. 25\%). The results of this study indicated that intestinal parasites would be responsible for the digestive disorders in the children. Several authors Zerbo (2012), Basavaraj et al., (2012), Assefa et al., (2009) found respectively $57.14 \%$, $60.68 \%$ and $52.3 \%$ in saddles diarrheic of the HIV-positive patients.

Children classification by immunology stage in relation to intestinal parasite infection showed a relatively higher prevalence of intestinal parasitic infection in children who had an absence of immunizing deficit.

It could be explained by the fact that in this study, the majority of the children had an absence of immunizing deficit. There was no significant relationship between immune status and intestinal parasites. This finding agrees with previous report (Fekadu et al., 2013; Fregonesi et al., 2015) but contradicts other reports which showed higher infestation rate in patients with severe immunosuppression (Akinbo et al., 2011; Obateru et al., 2016; Kaniyarakkal et al., 2016). These previous observations let envisage that the immunizing deficit would be a factor favoring the parasitic infections.

Cotrimoxazole use was found to be protective against occurrence of opportunistic infections, although the association was not statistically significant with intestinal parasites. This is similar to those reported by Ringo et al., (2015). That could also mean that the parasites isolated in the present study are not sensitive to the drug administered to the children. 
Table.1 Clinical, therapeutic, biological and socio-demographic characteristics and relationship with intestinal parasites

\begin{tabular}{|c|c|c|c|c|}
\hline Characteristics & Number & Infected number & Percentage & p-value \\
\hline Age & & & & \\
\hline 0 -5 years & 17 & 1 & 23.53 & 0.23 \\
\hline >5 - 10 years & 47 & 13 & 29.79 & 0.06 \\
\hline >10- 15 years & 29 & 9 & 17.24 & 0.21 \\
\hline $\begin{array}{c}\text { Digestive disorders } \\
\text { Presence }\end{array}$ & 13 & 10 & 73.92 & 0.00 \\
\hline Absence & 80 & 13 & 16.25 & \\
\hline Immunology stage & & & & \\
\hline Absence of immunizing deficit & 63 & 17 & 26.98 & 0.15 \\
\hline Moderate immunizing deficit & 11 & 2 & 18.18 & 0.45 \\
\hline Advanced immunizing deficit & 8 & 2 & 25.00 & 0.63 \\
\hline Severe immunizing deficit & 11 & 2 & 18.18 & 0.45 \\
\hline Drugs Administered & & & & \\
\hline ART \& CTX & 76 & 21 & 27.63 & 0.14 \\
\hline CTX & 13 & 1 & 7.69 & 0.11 \\
\hline
\end{tabular}

ART: antiretroviral; CTX: Cotrimoxazole

Table.2 Relative prevalence of intestinal parasites among children.

\begin{tabular}{|l|c|c|}
\hline \multicolumn{1}{|c|}{ Species parasitic } & Positive samples & Prevalence (\%) \\
\hline Entamoeba coli & 12 & 12.90 \\
\hline Entamoeba histolytica & 1 & 1.07 \\
\hline Giardia intestinalis & 2 & 2.15 \\
\hline Trichomonas intestinalis & 5 & 5.38 \\
\hline E. coli $+\boldsymbol{T}$. intestinalis & 2 & 2.15 \\
\hline E. coli $+\boldsymbol{T}$. intestinalis + E. histolitica & 1 & 1.07 \\
\hline
\end{tabular}

Table.3 Relationship between digestive disorders and intestinal parasites

\begin{tabular}{|c|c|c|c|c|c|c|}
\hline $\begin{array}{c}\text { Digestive } \\
\text { disorders }\end{array}$ & E.coli & T. intestinalis & G. intestinalis & E.histolytica & $\begin{array}{c}\text { E. coli }+ \\
\text { T. intestinalis }\end{array}$ & $\begin{array}{c}\text { E. coli }+ \\
\text { E. histolitica } \\
+ \text { T. intestinalis }\end{array}$ \\
\hline Absence & 13.75 & - & 1.25 & - & 1.25 & 4.34 \\
\hline Presence & $\mathbf{7 . 7 0}$ & $\mathbf{3 8 . 4 8}$ & $\mathbf{7 . 7 0}$ & $\mathbf{7 . 7 0}$ & 15.38 & - \\
\hline p-value & $\mathbf{0 . 4 7}$ & $\mathbf{0 . 0 0}$ & $\mathbf{0 . 0 1}$ & $\mathbf{0 . 1 2}$ & $\mathbf{0 . 2 6}$ & $\mathbf{0 . 8 6}$ \\
\hline
\end{tabular}

Entamoeba coli exhibited the highest prevalence (12.9 \%), followed by Trichomonas intestinalis (5.38 \%), Giardia intestinalis (1.07\%), Entamoeba histolytica
(1.07\%). The intestinal parasitism of the child in this study is composed of protozoa, parasites of the dirty hands, the fecal danger and the soiled food. Giardia intestinalis and 
Trichomonas intestinalis species were significantly associated with digestive disorders. This is in agreement with other observations reported by some authors (Nantes et al., 2005; Meloni et al., 2011).

In spite of the ARV treatment and disease prevention with CTX, the prevalence of the intestinal parasites in the HIV positive children is moderately high. Therefore, health education would be the best way to prevent from intestinal parasite infections which are mainly food borne diseases. Screening children for intestinal parasites should continue independently to their immunology stage for rapid management with regard to the high mortality and morbidity of these infections.

\section{Acknowledgement}

All authors thank to all staff for the service of Parasitology-Mycology and the department for general pediatry of the University hospital Center Yalgado Ouédraogo without forgetting the patients living with the VIH.

\section{References}

Akinbo, F. O., Okaka, C. E., and Omoregie, R. 2011. Prevalence of intestinal parasites in relation to CD4 counts and anaemia among HIV-infected patients in Benin City, Edo State, Nigeria. Tanzania journal of health research, 13(1): 8-13.

Amer, H O., Ashankyty, I. M. andHaouas, N. A. 2016. Prevalence of intestinal parasite infections among patients in local public hospitals of Hail, North western Saudi Arabia. Asian Pacific journal of tropical medicine, 9(1) :4448.

Assefa, S., Erko B., Medhin, G., Assefa, Z. and Shimelis, T. 2009. Intestinal parasitic infections in relation to HIV status, diarrhoea and CD4 T-Cell count.
BMC Infectious Diseases,18 (9):155160.

Basavaraj, S., Shepur, T. A., Shashidhar, V., Nandi, A S., Amareshwar, S M. 2012. Intestinal parasitic infestations in HIV seropositive children. International Journal of Pharma and Bio Sciences,3(2):293-299.

Casemore, D P. 1991. Laboratory methods for diagnosing cryptosporidiosis. Journal of Clinical Pathology,44:445-451

Cheesbrough, M. 1999.Parasitological Tests. Cambridge University Press pp 178-309

Cissé, M., Coulibaly S., Guiguemde R. 2011. Epidemiological features of intestinal parasitic infection in Burkina Faso from 1997 to 2007. Medecine tropicale, 71(3):257-60.

Farthing, M J G. 2006. Treatment options for the eradication of intestinal protozoa. Nature Clinical Practice Gastroenterology and Hepatology,3: 436-445

Fekadu, S., Taye, K., Teshome, W. and Asnake, S. 2013. Prevalence of parasitic infections in HIV-positive patients in southern Ethiopia: A cross-sectional. Study. Journal of Infection in Developing Countries,7(11): 868-872.

Fortunato, S., Castagna, B., Monteleone, M R., Pierro, R., Cringoli, G. and Bruschi, F. 2014. Parasite prevalence in a village in Burkina Faso: the contribution of new Techniques. Journal of Infection in Developing Countries, 8(5):670-675.

Fregonesi, B M., Suzuki, M N., Machado, C S., Tonani, K A., Fernandes, A P., Monroe, A A., Cervi, M C. and SeguraMuñoz, S. 2015. Emergent and reemergent parasites in HIV-infected children:immunological and socioenvironmental conditions that are involved in the transmission of Giardia spp. and Cryptosporidium spp. Revista da Sociedade Brasileira de Medicina Tropical, 48 (6): 753-758. 
Harhay, M., Horton, J. and Olliaro, P. 2010. Epidemiology and control of human gastrointestinal parasites in children. Expert Review of Anti-infective Therapy, 8(2):219-34.

Jayalakshmi, S. and Dharanidevi, S. 2016. The Prevalence of Intestinal Parasitic Infections in a Tertiary Care Hospital in Southern India - A Retrospective Study. International Journal of Current Microbiology and Applied Sciences, 5(10) : 718-723.

Kaniyarakkal, V., Mundangalam, N., Moorkoth, A. P., and Mathew, S. 2016. Intestinal Parasite Profile in the Stool of HIV Positive Patients in relation to Immune Status and Comparison of Various Diagnostic Techniques with Special Reference to Cryptosporidium at a Tertiary Care Hospital in South India. Advances in medicine, $2016: 3564359$.

Karou, S., Sanou, D., Ouermi, D., Pignatelli, S., Pietra, V., and Moret R. 2011. Enteric parasites prevalence at Saint Camille Medical Centre in Ouagadougou, Burkina Faso. Asian Pacific Journal of Tropical Medicine, 4(5):401-3.

Kipyegen, C K., Shivairo, R S. and Odhiambo, R O. 2012. Prevalence of intestinal parasites among HIV patients in Baringo, Kenya.Pan African Medical Journal, $13: 37$.

Meloni, D., Mantini, C., Goustille, J., Desoubeaux, G., Maakaroun-Vermesse, Z., Chandenier, J.,Gantois, N., Duboucher, C., Fiori, P. L., Dei-Cas, E., Duong, T H. and Viscogliosi, E.2011. Molecular identification of Pentatrichomonas hominis in two patients with gastrointestinal symptoms. Journal of Clinical Pathology,64 (Goustille, J) : 933-935.

Nantes, O., Zozaya, J M., Prieto, C., Beloqui R. and Arín A. 2005. General malaise and diarrhea as the main manifestations of Giardia lamblia infection. Gastroenterol Hepatol, 28(9):558-60.

Obateru, O A., Bojuwoye, B J., Olokoba, A B, Fadeyi, A., Fowotade, A., Olokoba, L B. 2017. Prevalence of intestinal parasites in newly diagnosed HIV/AIDS patients in Ilorin, Nigeria. Alexandria Journal of Medicine, 53(2):111-116.

Oguntibeju, O O. 2006. Prevalence of intestinal parasites in HIVpositive/AIDS patients in South Africa. Malaysian Journal of Medical Sciences, 13(1) : 68-73.

ONUSIDA/BF. 2015. Global aids response progress reporting 2014. Available at http://www.unaids.org/sites/default/files /country/documents//file\%2C94412\%2C fr.pdf[accessed: 11-12-2016]

Ouermi D, Karou D S, Ouattara I, Gnoula C., Pietra V., and Moret R., 2012. [Prevalence of intestinal parasites at Saint-Camille medical center in Ouagadougou (Burkina Faso), 1991 to 2010]. Medecine et Sante Tropicales, 22(1) :40-44

Oyedeji, O A, Adejuyigbe, E., Oninla, S O., Akindele, A A., Adedokun, S A., Agelebe, E. 2015. Intestinal Parasitoses in HIV Infected Children in a Nigerian Tertiary Hospital. Journal of Clinical and Diagnostic Research, 9 (11): SC01SC05.

Ringo, T A., Ernestb, A., Kamalac, B. and Mpondod, B. C. T. 2015. Intestinal parasitic infections and the level of immunosuppression in HIV seropositive individuals with diarrhoea in Kilimanjaro, Tanzania: A cross sectional study. South Sudan Medical Journal,8(3) :52-56.

Sangaré, I., Bamba, S., Cissé, M., Zida, A., Bamogo, R., Sirima, C., Yaméogo, B. K., Sanou, R., Drabo, F., Dabiré, R. K., and Guiguemdé, R. T. 2015. Prevalence of intestinal opportunistic parasites infections in the University hospital of 
Bobo-Dioulasso, Burkina Faso. Weber, R., Bryan, R T., Owen, R L., Wilcox, Infectious diseases of poverty, 4:32-38.

Singh, R., Singla, P., and Sharma, M. 2013. Prevalence of Intestinal Parasitic Infections in a Tertiary Care Hospital in Northern India: Five-year retrospective study. International Journal of Current Microbiology and Applied Sciences, 2(10) : $112-117$.

C M., and Gorelkin L. 1992. Improved light-microscopical detection of microsporidia spores in stool and duodenal aspirates. The Enteric Opportunistic Infections Working Group. New England Journal of Medicine, 326: 161-166.

\section{How to cite this article:}

Traoré Roukiatou, Zongo Cheikna, Zongo Oumarou, Ouédraogo Ganamé Abasse, Zida Adama, Yonaba Caroline, Traoré Yves and Savadogo Aly. 2021. Prevalence of Intestinal Opportunistic Parasites Infections among HIV Positive Children in the University Hospital Center Yalgado Ouédroago of Ouagadougou, Burkina Faso. Int.J.Curr.Microbiol.App.Sci. 10(10): 550-557. doi: https://doi.org/10.20546/ijcmas.2021.1010.065 